\title{
Selective Mono- and Dimetallation of a Group 3 Sandwich Complex
}

Received 00th January 20xx

Antonio J. Martínez-Martínez, Alan R. Kennedy, Valerie Paprocki, Felipe Fantuzzi, Rian D.

Accepted 00th January 20xx

Dewhurst, Charles T. O'Hara, Holger Braunschweig,* Robert E. Mulvey*

DOI: $10.1039 / \times 0 x \times 00000 x$

\begin{abstract}
The scandium $\mathrm{Cp} / \mathrm{COT}$ hybrid sandwich compound [ $\left(\eta^{5}\right.$ $\left.\left.\mathrm{C}_{5} \mathrm{H}_{5}\right) \mathrm{Sc}\left(\eta^{8}-\mathrm{C}_{8} \mathrm{H}_{8}\right)\right]$ is resistant to metallation via conventional alkyllithium and lithium amide bases. In this work, clean, selective, stoichiometric and high-yielding mono- and dimetallation is accomplished using tandem trans-metal-trapping (TMT) involving LiTMP and $i \mathrm{Bu}_{2} \mathrm{AITMP}$ with deprotonation occurring selectively at the $\mathrm{Cp}$ and $\mathrm{Cp} / \mathrm{COT}$ rings respectively, providing the first example of selective metallation of a sandwich complex featuring a Group 3 element.
\end{abstract}

While the functionalization of ferrocene ${ }^{1}$ and related $\mathrm{Cp}\left(\mathrm{C}_{5} \mathrm{H}_{5}{ }^{-}\right.$, cyclopentadienyl)-based metallocenes is well established, the functionalization of sandwich complexes with COT $\left(\mathrm{C}_{8} \mathrm{H}_{8}{ }^{2-}\right.$, cyclooctatetraendiide) ligands is significantly more challenging and therefore known methods are still relatively scarce. ${ }^{2}$ Deprotonative metallation is a common tool used for opening up carbon sites in sandwich compounds for functionalization. ${ }^{3}$ Ferrocene can be monometallated or dimetallated with varying degrees of selectivity depending on the choice of polar organometallic base [e.g., $\left.n \mathrm{BuLi} \cdot \mathrm{TMEDA}, t \mathrm{BuLi} \cdot(\mathrm{KO} t \mathrm{Bu})_{\mathrm{x}}\right]^{4}{ }^{4}$ Its controlled tetrametallation is achievable via the synergistic bimetallic mixture ${ }^{5} n \mathrm{BuNa} / n, s \mathrm{Bu}_{2} \mathrm{Mg} / 3 i \mathrm{Pr}_{2} \mathrm{NH}{ }^{6}$ while excess $n$ BuK can allow attachment of up to eight metal atoms on its carbon scaffold. ${ }^{7}$ Selective dimetallation is particularly attractive since it can provide access to ansa complexes, which

\footnotetext{
a. Dr. A. J. Martínez-Martínez

Supramolecular Organometallic Chemistry Laboratory

CIQSO-Center for Research in Sustainable Chemistry \& Department of Chemistry University of Huelva

Campus El Camen, 21007 Huelva, Spain

b. Dr. A. R. Kennedy, Dr. C. T. O'Hara, Prof. Dr. R. E. Mulvey

WestCHEM, Department of Pure and Applied Chemistry

University of Strathclyde

Glasgow, G1 1XL, U.K

E-mail:r.e.mulvey@strath.ac.uk

V. Paprocki, Dr. F. Fantuzzi, Dr. R. D. Dewhurst, Prof. Dr. H. Braunschweig Institute for Inorganic Chemistry and Institute for Sustainable Chemistry \& Catalysis with Boron

Julius-Maximilians-Universität Würzburg

Am Hubland, 97074 Würzburg, Germany

E-mail: h.braunschweig@uni-wuerzburg.de
}

Electronic Supplementary Information (ESI) available: synthetic, spectroscopic computational and crystallographic details. See DOI: 10.1039/x0xx00000x are convenient monomers for ring-opening polymerization (ROP) reactions. ${ }^{8}$ This reaction protocol has been successfully transferred to heteroleptic ligand systems, i.e. complexes of the composition $\left[\left(\eta^{5}-\mathrm{C}_{5} \mathrm{H}_{5}\right) \mathrm{M}\left(\eta^{7}-\mathrm{C}_{7} \mathrm{H}_{7}\right)\right]$, of which both ansa complexes and ring-opened polymers have been reported. ${ }^{9}$ In 2011 the group of Braunschweig used a metallation protocol consisting of $n \mathrm{BuLi}$ and the activating oligoamine $N, N, N^{\prime}, N^{\prime \prime}, N^{\prime \prime}$ pentamethyldiethylenetriamine (PMDTA) in $n$-hexane to synthesize a unique ansa-bridged cyclooctatetraenide complex of composition [ $\left.\mathrm{Ti}\left(\eta^{5}-\mathrm{C}_{5} \mathrm{H}_{4} \mathrm{Li}\right)\left(\eta^{8}-\mathrm{C}_{8} \mathrm{H}_{7} \mathrm{Li}\right)\right] \cdot \mathrm{PMDTA},{ }^{2}$ and this ligand system is of particular interest due to its widespread use in $d$-block metal chemistry. ${ }^{10}$ However, this same approach was unsuccessful when applied to the heteroleptic scandium $\mathrm{Cp} / \mathrm{COT}$ sandwich compound $\left[\left(\eta^{5}-\mathrm{C}_{5} \mathrm{H}_{5}\right) \mathrm{Sc}\left(\eta^{8}-\mathrm{C}_{8} \mathrm{H}_{8}\right)\right] \quad$ (1). ${ }^{11}$ Varying the organolithium reagent used ( $n \mathrm{BuLi}, t \mathrm{BuLi}$, LiNiPr${ }_{2}$, $n \mathrm{BuLi} \cdot \mathrm{KO}$ tBu), its stoichiometric excess, the activating donor molecule (TMEDA, PMDTA, THF), and the reaction conditions (temperatures and reaction time, some even up to 5-7 days) also proved ineffective, providing either no metallation at all or poor yields of dimetallated products $(3-11 \%)$ in complex mixtures. Thus we turned our attention to the accomplished toolbox of metallating agents developed by the group of Mulvey, which includes examples specifically engineered for effecting efficient dimetallation. ${ }^{12}$ Herein we report the outcomes of reacting a selection of these agents with [ $\left(\eta^{5}\right.$ $\left.\left.\mathrm{C}_{5} \mathrm{H}_{5}\right) \mathrm{Sc}\left(\eta^{8}-\mathrm{C}_{8} \mathrm{H}_{8}\right)\right]$ (1).

First, the reactivity of $\mathbf{1}$ with the heterobimetallic sodium magnesiates $\quad[(\mathrm{TMEDA}) \mathrm{Na}(n \mathrm{Bu})(\mathrm{TMP}) \mathrm{Mg}(\mathrm{TMP})]^{13}$ and $\left[\mathrm{Na}_{6} \mathrm{Mg}_{2} \mathrm{TMP}_{6} n \mathrm{Bu}_{2}\right]^{14}$ (TMP $=$ 2,2,5,5-tetramethylpyrrolidide) was studied, with the latter chosen due to its template ring structure that has been found a perfect fit to selectively dimetallate a series of arenes. Unfortunately, in both cases the resulting experimental data did not show promise as mixtures were obtained under diverse stoichiometries and reaction conditions. Second, the reactivity of $\mathbf{1}$ with bulky lithium amides was explored. ${ }^{15}$ Equimolar amounts of $\mathbf{1}$ and LiTMP ${ }^{16}$ in $n$ hexane gave only low in situ yields $(9 \%$ or $11 \%$ after $24 \mathrm{~h}$ at room temperature or $12 \mathrm{~h}$ under reflux conditions, respectively, as evidenced by in situ ${ }^{1} \mathrm{H}-\mathrm{NMR}$ monitoring) of the singly 
metallated product $\left[\mathrm{Li}\left\{\left(\eta^{5}-\mathrm{C}_{5} \mathrm{H}_{4}\right) \mathrm{Sc}\left(\eta^{8}-\mathrm{C}_{8} \mathrm{H}_{8}\right)\right\}\right] 2$ (Scheme 1). Here monolithiation occurs preferentially at the $\mathrm{Cp}$ ring, leaving the COT ring untouched.

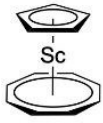

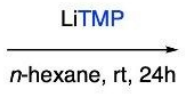

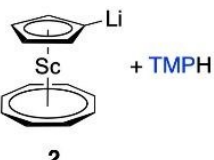

Scheme 1. Metallation of $\left[\left(\eta^{5}-\mathrm{C}_{5} \mathrm{H}_{5}\right) \mathrm{Sc}\left(\eta^{8}-\mathrm{C}_{8} \mathrm{H}_{8}\right)\right]$ with LiTMP to give $\left[\mathrm{Li}\left\{\left(\eta^{5}-\mathrm{C}_{5} \mathrm{H}_{4}\right) \mathrm{Sc}\left(\eta^{8}-\mathrm{C}_{8} \mathrm{H}_{8}\right)\right\}\right]$

This modest but significant result was promising as trans-metaltrapping (TMT) protocols can promote enhanced metallation in reactions where the conversion is low. ${ }^{17}$ In TMT, LiTMP remains separated from $i \mathrm{Bu}_{2} \mathrm{AlTMP}$ in hydrocarbon solution or THF solution rather than forming an ate complex of type "(THF $)_{n} \mathrm{Li}(\mathrm{TMP}) \mathrm{Al}(i \mathrm{Bu})_{2}(\mathrm{TMP})$ ". Thus, free LiTMP can operate as a base to lithiate substrates in low yields, while the more carbophilic $\mathrm{BBu}_{2} \mathrm{AITMP}$.THF can trap and stabilize the generated carbanion and drive equilibria to the product side to achieve much higher lithiation conversions. Given the success of the TMT strategy with other systems, we sought to determine if a similar strategy could enable metallation of the challenging scandium sandwich compound 1 . Thereby, reaction of LiTMP/iBu 2 AlTMP/THF (1.2 equiv.) with 1 (1 equiv.) yielded monometallated

[THF-Li $(\mu$-TMP $)\left\{\mu-\left\{\left(\eta^{5}-\mathrm{C}_{5} \mathrm{H}_{5}\right) \mathrm{Sc}\left(\eta^{8}-\right.\right.\right.$ $\left.\left.\left.\left.\mathrm{C}_{8} \mathrm{H}_{8}\right)\right\}\right\} \mathrm{Al}(i \mathrm{Bu})_{2}\right] \mathbf{3}$ in near quantitative in situ yield in refluxing $n$ hexane for 12 hours (Scheme 2).

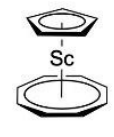

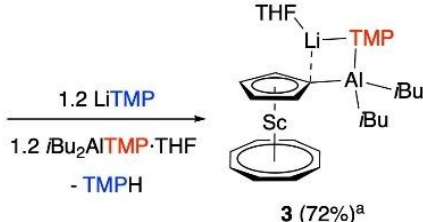

Scheme 2. Metallation of $\left[\left(\eta^{5}-\mathrm{C}_{5} \mathrm{H}_{5}\right) \mathrm{Sc}\left(\eta^{8}-\mathrm{C}_{8} \mathrm{H}_{8}\right)\right] \quad \mathbf{1}$ with LiTMP/iBu 2 AITMP/THF (1.2 equiv) to give 3 . a Isolated yield, ful conversion by NMR.

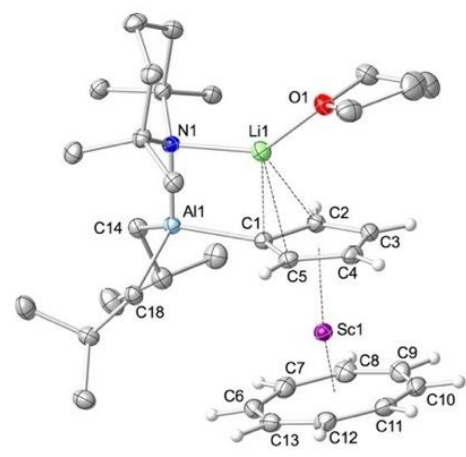

Figure 1. Molecular structure of [THF-Li $(\mu-\mathrm{TMP})\left\{\mu-\left\{\left(\eta^{5}-\mathrm{C}_{5} \mathrm{H}_{4}\right) \mathrm{Sc}\left(\eta^{8}\right.\right.\right.$ $\left.\left.\left.\mathrm{C}_{8} \mathrm{H}_{8}\right)\right\}\right\} \mathrm{Al}\left((\mathrm{Bu})_{2}\right]$ (3). Displacement ellipsoids are displayed at 35\% probability. Hydrogen atoms, except those on the $\left\{\left(\mathrm{C}_{5} \mathrm{H}_{4}\right) \mathrm{Sc}\left(\mathrm{C}_{8} \mathrm{H}_{8}\right)\right\}$ unit, are omitted for clarity. Dashed lines illustrate $\mathrm{Li} \cdots \mathrm{C}$ and Sc...centroid interactions.
Complex 3, isolated as a solid (72\%) or as/crystats/(66\%),32mas characterized in the solid state by X-ray diffraction analysis (Figure 1 ) and in solution by ${ }^{1} \mathrm{H},{ }^{13} \mathrm{C}$ and ${ }^{7} \mathrm{Li} \mathrm{NMR}$ spectroscopy (Figures S2-S8, spectroscopic assignments were performed, in some cases, via ${ }^{13} \mathrm{C}\left\{{ }^{1} \mathrm{H}\right\}$-DEPT $135,{ }^{1} \mathrm{H},{ }^{1} \mathrm{H}$-COSY $,{ }^{1} \mathrm{H},{ }^{13} \mathrm{C}-\mathrm{HMQC}$ and ${ }^{1} \mathrm{H},{ }^{13} \mathrm{C}-\mathrm{HMBC}$ experiments). Also, the aggregation of $\mathbf{3}$ in $\left[\mathrm{D}_{8}\right] \mathrm{THF}$ was studied by ${ }^{1} \mathrm{H}$ DOSY NMR spectroscopy (Figure S22) with the $\mathrm{MW}_{\text {Dosy }}$ determinations (within experimental error < $10 \%)$ suggesting that the solid-state structure of $\mathbf{3}$ is retained in solution. ${ }^{18}$ Satisfactory elemental analyses were also obtained for 3. Attempts to dimetallate $\mathbf{1}$ with two equivalents of the TMT system LiTMP/iBu ${ }_{2}$ AITMP/THF in all cases gave mixtures of the monometallated and dimetallated species 3 and [ $\{\mathrm{THF} \cdot \mathrm{Li}(\mu-$ TMP)Al( $\left.\left.\left.(i \mathrm{Bu})_{2}\right\}_{2}\left\{\mu-\left\{\eta^{5}-\mathrm{C}_{5} \mathrm{H}_{4}\right) \mathrm{Sc}\left(\eta^{8}-\mathrm{C}_{8} \mathrm{H}_{7}\right)\right\}\right\}\right] \quad$ (4), in an approximately 0.4:0.6 molar ratio, as shown by NMR spectroscopy (Figure S17, S18, S20). Both $n$-hexane and methylcyclohexane were the solvents of choice for the studies and the reactions were tested under reflux conditions with varying reaction times. On reaching the 0.4:0.6 molar ratio the reaction did not progress towards 4 , even with longer reaction times in refluxing $n$-hexane $\left(\mathrm{bp} 68^{\circ} \mathrm{C}\right)$ or methylcyclohexane (bp $101{ }^{\circ} \mathrm{C}$ ). A second process occurring in solution was found to consume the base-trap mixture $\mathrm{LiTMP} / \mathrm{iBu}_{2} \mathrm{AlTMP} / \mathrm{THF}$ by approximately $20 \%$ under these reaction conditions. A more rigorous NMR study of the in situ reaction revealed that $\alpha$ metallation of THF was in competition with metallation of $\mathbf{1}$ under these reaction conditions. ${ }^{19}$ Compound 5, [\{THF.Li $(\mu-$ TMP)Al( $\left.\left.(i \mathrm{Bu})_{2}\right\}\left(\mu-\mathrm{C}_{4} \mathrm{H}_{7} \mathrm{O}\right)\right]$, was detected in approximately $10 \%$ with respect to $\mathbf{3}$ and $\mathbf{4}$ by NMR spectroscopic investigations (Figure S20). ${ }^{20}$ To form 5 two THF molecules are required; therefore, a maximum $10 \%$ of $\mathbf{5}$ can be formed. Free LiTMP and $i \mathrm{Bu}_{2} \mathrm{AlTMP}$ (10\% both) balance the equation (Scheme 3$)$.

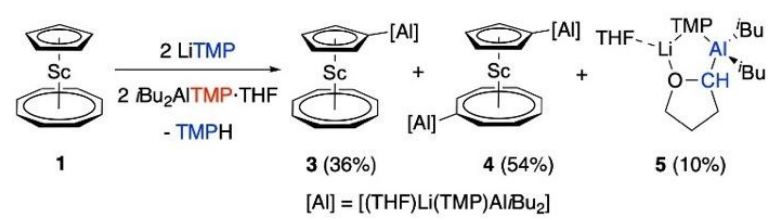

Scheme 3. Metallation of $\left[\left(\eta^{5}-\mathrm{C}_{5} \mathrm{H}_{5}\right) \mathrm{Sc}\left(\eta^{8}-\mathrm{C}_{8} \mathrm{H}_{8}\right)\right]$ (1) with LiTMP/iBu 2 AlTMP/THF (2 equiv.) to give $\mathbf{3}, \mathbf{4}$ and $\mathbf{5}$.

Next, three molar equivalents of the TMT system $\mathrm{LiTMP} / \mathrm{BBu}_{2} \mathrm{AITMP} / \mathrm{THF}$ were found to satisfactorily dimetallate 1 in methylcyclohexane under reflux conditions $\left(101^{\circ} \mathrm{C}\right)$ for 3.5 hours. This transformation produced 4 (Scheme 4) in near quantitative yield as evidenced from ${ }^{1} \mathrm{H}$ and ${ }^{13} \mathrm{C}$ NMR spectra, with total absence of either $\mathbf{1}$ or $\mathbf{3}$ in the product mixtures (Figure S17 and S18). As discussed above, approximately 2.2 molar equivalents of "LiTMP/iBu ${ }_{2}$ AITMP/THF" would be enough to compensate the loss of the metallating reagent by reaction with THF, but by adding a slight excess of metallating reagent ( 3 equiv.) full conversion of $\mathbf{1}$ to $\mathbf{4}$ was accomplished.

Longer reaction times than $3.5 \mathrm{~h}$ under reflux conditions in methylcyclohexane gave complicated NMR spectra, probably due to degradation of $\mathbf{4}$ at high temperatures, while shorter reaction times gave lower in situ conversions for the 
transformation of $\mathbf{1}$ to $\mathbf{4}$ with varying amounts of $\mathbf{3}$ seen in the reaction mixtures. When $\mathbf{1}$ was reacted with "LiTMP/iBu 2 AITMP/THF" in a 1:3 molar ratio in hexane (instead of methylcyclohexane) under reflux conditions (bp $68^{\circ} \mathrm{C}$ ) the transformation of $\mathbf{1}$ to $\mathbf{4}$ was incomplete and $\mathbf{3}$ is also detected in solution (Figure S19). It seems that $\mathbf{4}$ is only efficiently obtained at temperatures in excess of that possible with boiling $n$-hexane $\left(68^{\circ} \mathrm{C}\right)$ and short periods of time $(3.5 \mathrm{~h})$ are needed to ensure near quantitative conversions.

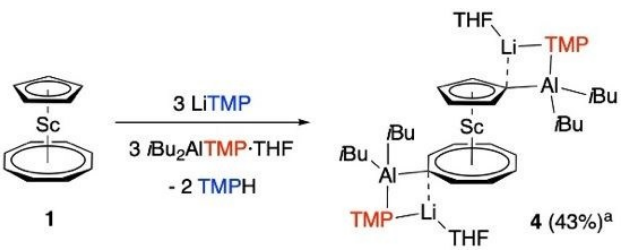

Scheme 4. Metallation of $\left[\left(\eta^{5}-\mathrm{C}_{5} \mathrm{H}_{5}\right) \mathrm{Sc}\left(\eta^{8}-\mathrm{C}_{8} \mathrm{H}_{8}\right)\right]$ (1) with conversion by NMR spectroscopy.

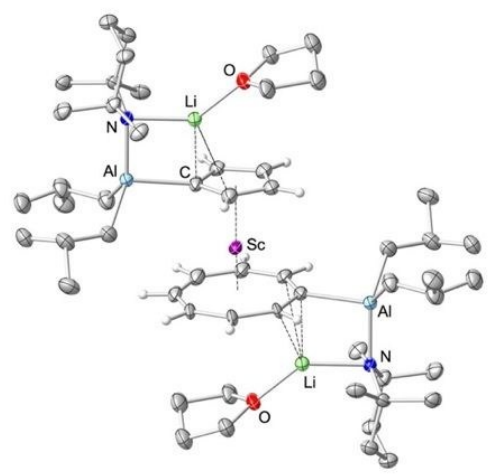

Figure 2. Molecular structure of [\{THF-Li( $\mu$-TMP)Al(iBu $\left.)_{2}\right\}_{2}\left\{\mu-\left\{\left(\eta^{5}-\right.\right.\right.$ $\left.\left.\left.\left.\mathrm{C}_{5} \mathrm{H}_{4}\right) \mathrm{Sc}\left(\eta^{8}-\mathrm{C}_{8} \mathrm{H}_{7}\right)\right\}\right\}\right] 4$ displaying its atom connectivity. Hydrogen atoms, except on the $\left\{\left(\mathrm{C}_{5} \mathrm{H}_{4}\right) \mathrm{Sc}\left(\mathrm{C}_{8} \mathrm{H}_{7}\right)\right\}$ unit, and all disordered components are omitted for clarity. Displacement ellipsoids are displayed at $30 \%$ probability. The dashed lines illustrate $\mathrm{Li} \cdots \mathrm{C}$ and Sc...centroid interactions.

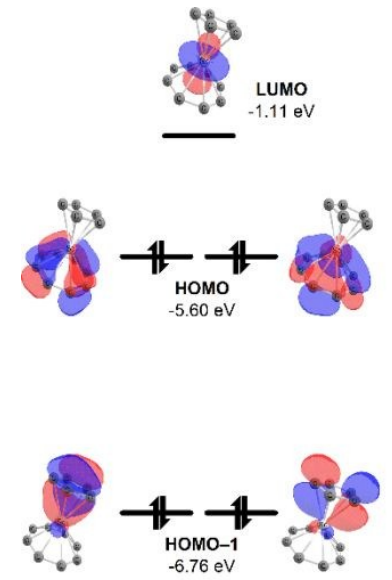

1
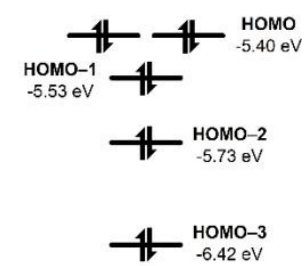
HOMO-4
$-6.80 \mathrm{eV}$

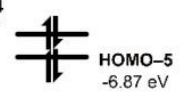

3
Figure 3. Frontier molecular orbitals of $\mathbf{1}$ (left) and $\mathbf{3}$ (right) at the B3LYP/6-311++G** level of theory. Orbital energies are in eV.

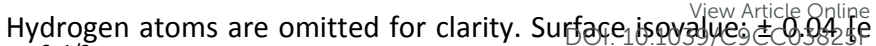
$\left.a_{0}^{-3}\right]^{1 / 2}$.

The dimetallated sandwich complex $\mathbf{4}$ was isolated as orange crystals in a modest yield of $43 \%$. Complex 4 exhibited high solubility in hydrocarbons at ambient temperature, which hindered its isolation in high yields. While $\mathbf{4}$ was crystallographically characterized (Figure 2), heavy disorder of the entire molecular structure prevents a discussion of the metric parameters. In addition, 4 was fully characterized in solution by ${ }^{1} \mathrm{H},{ }^{13} \mathrm{C}$ and ${ }^{7} \mathrm{Li}$ NMR spectroscopy (Figure S9-16, spectroscopic assignments were performed, in some cases, via ${ }^{13} \mathrm{C}\left\{{ }^{1} \mathrm{H}\right\}$-DEPT135, ${ }^{1} \mathrm{H},{ }^{1} \mathrm{H}$-COSY, ${ }^{1} \mathrm{H},{ }^{13} \mathrm{C}-\mathrm{HMQC}$ and ${ }^{1} \mathrm{H},{ }^{13} \mathrm{C}-\mathrm{HMBC}$ experiments). Furthermore, the aggregation state of $\mathbf{4}$ in $\left[D_{8}\right]$ THF solution (for comparison with 3 ) was studied by ${ }^{1} \mathrm{H}$ DOSY NMR spectroscopy (Figure S24). Akin to $\mathbf{3}$ and within an accepted experimental error for $\mathrm{MW}_{\text {DOSY }}$ determinations (< $10 \%)$, the ${ }^{1} \mathrm{H}$ DOSY NMR spectra were in agreement with the retention of the solid-state structure of 4 in $\left[D_{8}\right]$ THF solution. Satisfactory elemental analyses were also obtained for $\mathbf{4}$.

The next challenge was to find a method of cleanly cleaving the carbon-aluminium bonds in the metallated systems. So far, attempts to react $\mathbf{3}$ and $\mathbf{4}$ with various stoichiometric quantities of electrophiles such as $\mathrm{D}_{2} \mathrm{O}, \mathrm{I}_{2}, \mathrm{TMSCl}$ and MeOTf, failed. These quenches generally resulted in intractable reaction mixtures as determined by mass spectrometry and NMR spectroscopy. In case of the silylation, the expected reaction products have been reported elsewhere ${ }^{11}$ and were thus easily identified using NMR spectroscopy. The reaction of $\mathbf{3}$ with iodine yielded very small amounts of a compound that sublimes at $130^{\circ} \mathrm{C}$, together with the reprotonated $\left[\left(\eta^{5}-\mathrm{C}_{5} \mathrm{H}_{5}\right) \mathrm{Sc}\left(\eta^{8}-\mathrm{C}_{8} \mathrm{H}_{8}\right)\right]$, but shows ${ }^{1} \mathrm{H} \mathrm{NMR}$ signals consistent with a monosubstituted sandwich complex (Figure S21). Additional sequestration of $\mathrm{Li}^{+}$, by adding 12crown-4, TMEDA or PMDTA during the quenching protocols also led to complicated reaction mixtures.
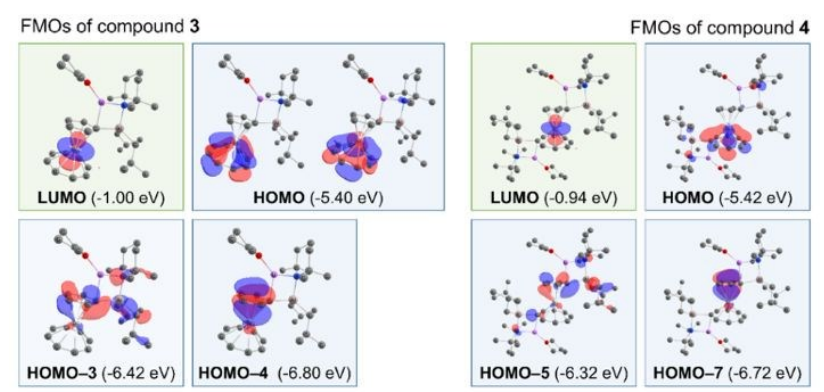

Figure 4. Frontier molecular orbitals of metallated species $\mathbf{3}$ (left) and 4 (right) at the B3LYP/6-311++G** level of theory. Orbital energies are in $\mathrm{eV}$. Hydrogen atoms are omitted for clarity. Surface isovalue: $\pm 0.04\left[\mathrm{e} \mathrm{a}_{0}^{-3}\right]^{1 / 2}$.

In an attempt to provide an explanation for the inconclusive quenching results we performed DFT calculations on the parent sandwich complex 1 (Figure 3, left, Figure S25) and both metallated congeners 3 and 4 (Figure 4, Figure S26). While the LUMO of the sandwich complex 1 comprises the metal- $d z^{2}$ orbital, the HOMO is composed of two degenerate orbitals of 
purely Sc-COT $\pi$-bonding character. The metalation of 1 with the Li/Al bimetallic system leads to very similar electronic situations in both the mono- and dimetallated species $\mathbf{3}$ and $\mathbf{4}$ (Figure 4). The HOMOs experience a destabilisation, with their basic shape remaining unchanged. The lower-lying molecular orbitals show spreading of electron density throughout the $\mathrm{Al} / \mathrm{Li}$ periphery, with significant electron density on the ring carbon atom present only in the HOMO-4 of compound 3 or the HOMO7 of compound 4, respectively. That the ring carbon atom is not present in the high-lying orbitals goes some way towards explaining the poor nucleophilic reactivity of $\mathbf{3}$ and $\mathbf{4}$.

In conclusion, facile selective metallation of the previously obstinate heteroleptic scandium sandwich compound $\mathbf{1}$ has been realized using a trans-metal-trapping approach. Depending on the reaction conditions, monometallation can be achieved selectively at the cyclopentadienide ring ligand, while dimetallation yields a $1,1^{\prime}$-substituted product. Due to the challenges encountered during studies of the reactivity of the metallated complexes, the electronic structure of the parent complex was investigated for the first time, in addition to its metallated derivatives, revealing the non-nucleophilic character of the ring-carbon atom. The success of this TMT method provides hope for further metallation chemistry of $d$ - and $f$ block sandwich complexes with inert $\mathrm{C}-\mathrm{H}$ bonds, which will open up new synthetic possibilities in metallocene chemistry.

The EPSRC (Career Acceleration Fellowship; EP/J001872/1 and EP/L001497/1), the Alexander von Humboldt (AvH) Foundation for a Research Award (to REM) and within the program Capes-Humboldt Research Fellowship for postdoctoral researchers (grant awarded to FF), and the Julius-MaximiliansUniversität Würzburg, are thanked for financial support.

\section{Conflicts of interest}

There are no conflicts to declare.

\section{Notes and references}

1 Ferrocenes, eds., A. Togni and T. Hayashi, VCH; Weinheim, 1995; N. J. Long, Metallocenes, Wiley-Blackwell, 1997.

2 H. Braunschweig, M. Fuss, T. Kupfer and K. Radacki, J. Am. Chem. Soc., 2011, 133, 5780 .

3 A. Bartole-Scott, H. Braunschweig, T. Kupfer, M. Lutz, I. Manners, T. Nguyen, K. Radacki and F. Seeler, Chem. Eur. J., 2006, 12, 1266; H. Braunschweig, T. Kupfer and K. Radacki, Angew. Chem., 2007, 119, 1655; Angew. Chem. Int. Ed., 2007, 46, 1630; H. Braunschweig, N. Buggisch, U. Englert, M. Homberger, T. Kupfer, D. Leusser, M. Lutz and K. Radacki, J. Am. Chem. Soc., 2007, 129, 4840; H. Braunschweig and T. Kupfer, Acc. Chem. Res., 2010, 43, 455; M. Schlosser in Organometallics in Synthesis, Third Manual (Ed.: M. Schlosser), John Wiley \& Sons, Weinheim, 2013, pp. 4-222.

4 R. Sanders and U. T. Mueller-Westerhoff, J. Organomet. Chem., 1996, 512, 219.

5 S. D. Robertson, M. Uzelac and R. E. Mulvey, Chem. Rev., 2019, 119, DOI: 10.1021/acs.chemrev.9b00047

6 W. Clegg, K. W. Henderson, A. R. Kennedy, R. E. Mulvey, C. T. O'Hara, R. B. Rowlings and D. M. Tooke, Angew. Chem. Int. Ed., 2001, 40, 3902; P. C. Andrikopoulos, D. R. Armstrong, W.
Clegg, C. J. Gilfillan, E. Hevia, A. R. Kennedy, R. View Article Online T. O'Hara, J. A. Parkinson and D. M. Tooke, J. Am. Chem. Soc., 2004, 126, 11612.

7 A. G. Osborne and R. H. Whiteley, J. Organomet. Chem., 1978, 162, 79.

8 D. A. Foucher, B. Z. Tang and I. Manners, J. Am. Chem. Soc., 1992, 114, 6246-6248; I. Manners, Adv. Organomet. Chem., 1995, 37, 113; B. Wang, Coord. Chem. Rev., 2006, 250, 242; I. Manners in Synthetic Metal-Containing Polymers, WileyVCH, Weinheim, 2004; D. E. Herbert, U. F. J. Mayer and I. Manners, Angew. Chem. Int. Ed., 2007, 46, 5060; C. J. Adams, H. Braunschweig, T. Kupfer, I. Manners, R. Richardson and G. Whittell, Angew. Chem., 2008, 120, 3886; Angew. Chem. Int. Ed., 2008, 47, 382; g) H. Brintzinger and D. Fischer, Adv. Polym. Sci., 2013, 258, 29.

9 H. Braunschweig, M. Lutz and K. Radacki, Angew. Chem., 2005, 117, 5792; Angew. Chem., Int. Ed., 2005 ,44,

5647; H. Braunschweig, M. Lutz, K. Radacki, A. Schaumlöffel, F. Seeler and C. Unkelbach, Organometallics, 2006, 25, 4433; M. Tamm, A. Kunst, T. Bannenberg, S. Randoll and P. G. Jones, Organometallics, 2007, 26, 417; H. Braunschweig, T. Kupfer, M. Lutz and K. Radacki, J. Am. Chem. Soc., 2007, 129, 8893; M. Tamm, Chem. Commun., 2008, 3089; S. K. Mohapatra, S. Bueschel, C. Daniliuc, P. G. Jones and M. Tamm, J. Am. Chem. Soc., 2009, 131, 17014; C. J. Adams, H. Braunschweig, M. Fuß, K. Kraft, T. Kupfer, I. Manners, K. Radacki and G. R. Whittell, Chem. Eur. J., 2011, 17, 10379; H. Braunschweig, A. Damme, S. Demeshko, K. Dück, T. Kramer, I. Krummenacher, F. Meyer, K. Radacki, S. StellwagKonertz and G. R. Whittell, J. Am. Chem. Soc., 2015, 137, 1492.

10 J. D. Jamerson, A. P. Masino and J. Takats, J. Organomet Chem., 1974, 65, C33; A. Westerhof and H. J. De Liefde Meijer, J. Organomet. Chem., 1976, 116, 319.

11 H. Braunschweig, A. Damme, K. Dück, I. Krummenacher, V. Paprocki, K. Radacki, J. Ramler, C. Schiller and C. Schneider, Chem. Eur. J. 2018, 24, 2403.

12 R. E. Mulvey, Acc. Chem. Res., 2009, 42, 743.

13 E. Hevia, D. J. Gallagher, A. R. Kennedy, R. E. Mulvey, C. T. O'Hara and C. Talmard, Chem. Commun., 2004, 2422.

14 A. J. Martinez-Martinez, A. R. Kennedy, R. E. Mulvey and C. T. O’Hara, Science, 2014, 346, 834; A. J. Martinez-Martinez, S. Justice, B. J. Fleming, A. R. Kennedy, I. D. H. Oswald and C. T. O'Hara, Science Adv., 2017, 3, e1700832.

15 R. E. Mulvey and S. D. Robertson, Angew. Chem. Int. Ed., 2013, 52, 11470.

16 M. F. Lappert, M. J. Slade, A. Singh, J. L. Atwood, R. D. Rogers and R. Shakir, J. Am. Chem. Soc., 1983, 105, 302; E. Hevia, A. R. Kennedy, R. E. Mulvey, D. L. Ramsay and S. D. Robertson, Chem. Eur. J., 2013, 19, 14069.

17 D. R. Armstrong, E. Crosbie, E. Hevia, R. E. Mulvey, D. L. Ramsay and S. D. Robertson, Chem. Sci., 2014, 5, 3031; W. Clegg, E. Crosbie, S. H. Dale-Black, E. Hevia, G. W. Honeyman, A. R. Kennedy, R. E. Mulvey, D. L. Ramsay and S. D. Robertson, Organometallics, 2015, 34, 2580; M. Uzelac and R. E. Mulvey, Chem. Eur. J., 2018, 24, 7786.

18 A. Macchioni, G. Ciancaleoni, C. Zuccaccia, D. Zuccaccia, Chem. Soc. Rev., 2008, 37, 479; D. Li, I. Keresztes, R. Hopson and P. G. Williard, Acc. Chem. Res., 2009, 42, 270; R. Neufeld, D. Stalke, Chem. Sci., 2015, 6, 3354.

19 A. R. Kennedy, J. Klett, R. E. Mulvey, D. S. Wright, Science, 2009, 326, 706.

20 E. Crosbie, P. Garcia-Alvarez, A. R. Kennedy, J. Klett, R. E. Mulvey and S. D. Robertson, Angew. Chem. Int. Ed., 2010, 49, 9388. 
TOC graphic:

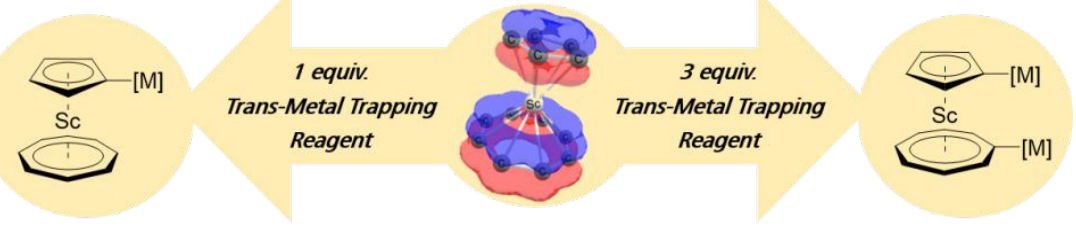

TOC text:

While lithium alkyls and lithium amides do not metallate the scandium compound [ $\eta^{5}$ $\left.\left.\mathrm{C}_{5} \mathrm{H}_{5}\right) \mathrm{Sc}\left(\eta^{8}-\mathrm{C}_{8} \mathrm{H}_{8}\right)\right]$, a synergistic lithium-aluminium base-trap partnership cannot resist taking a bite with one $\mathrm{C}-\mathrm{H}$ bond selectively cleaved from both $\mathrm{Cp}$ and COT rings. 